\title{
Two Case Studies of Topic- Related Multidimensional Reading Services in China
}

\author{
Huiyan Tang, Nanjing Agricultural University Library, Nanjing, China \\ Yitao Hu, Nanjing Agricultural University Library, Nanjing, China \\ Suoling Zhu, College of Humanities and Social Development at Nanjing Agricultural University, Nanjing, China \\ Weiwei Li, Institute of Higher Education at Tongji University, Shanghai, China \\ Qingkui Xi, Nanjing Agricultural University Library, Nanjing, China \\ Yuxian Liu, Institute of Higher Education at Tongji University, Shanghai, China \& School of History and Archives at \\ Yunnan University, Kunming, China
}

\begin{abstract}
This article provides a brief summary of the development of topic-related multidimensional reading services in academic libraries in China. The authors mainly introduce the methods and practices that Tongji University Library has developed for this type of service. The authors also include a briefing about a multidimensional reading service event called "Reading the city Jinling - the Red Mansions" which was hosted by Nanjing Agriculture University Library in 2017. Theoretical and practical explorations suggest that academic libraries could integrate more resources from different areas to promote a deeper understanding of reading, and to make more contributions to knowledge transformation and innovation in China.
\end{abstract}

\section{KEYWORDS}

Case Study, Cultural Heritage, Library, Reading Promotion, Topic-Related Multidimensional Reading

\section{INTRODUCTION}

Reading is an important way to acquire knowledge and gain wisdom. It is also an important channel for a country to develop its "cultural spirit" and inherited civilization. The Chinese people have a tradition of reading for thousands of years. They consider books as one of the most precious heritages, and pass this tradition to the younger generations. Currently, the Chinese government takes reading as an important measure to build a learning society. A nationwide reading campaign was initiated in 2006 with the goal that every resident will read in their life time. Nationwide Reading has been identified as a national development policy. Several regulations have already been made and legislation is being considered to guarantee the campaign's success (State Administration of Press, Publication, Radio, Film and Television, 2016).

This article, originally published under IGI Global's copyright on October 11, 2019 will proceed with publication as an Open Access article starting on January 20, 2021 in the gold Open Access journal, International Journal of Library and Information Services (converted to gold Open Access January 1, 2021), and will be distributed under the terms of the Creative Commons Attribution License (http://creativecommons.org/licenses/by/4.0/) which permits unrestricted use, distribution, and production in any medium, provided the author of the original work and original publication source are properly credited. 
A reading service is a traditional service provided by libraries. Encouraged by the "Nationwide Reading" policy, traditional libraries responded to this policy with enthusiasm, and organized various types of reading activities. The Library Society of China has set up two committees to promote nationwide reading: the Guidance Committee for the Popularization of Science and Reading, and the Reading Promotion Committee.

Libraries also actively extend the connotation of reading. Fan (2014) analyzed the basic theory of reading promotion and the new function of reading so that all citizens, including the people with reading difficulties, can enjoy reading. Zhang and Fan (2015) studied how China's public libraries should provide the reading service for visually impaired readers. In comparison, Western libraries go even further. Robertson (2008) introduced a healthy reading scheme to treat readers with mental health problems. Using books and reading, librarians make libraries a healthy workplace to provide therapy-based wellness programs (Tukhareli, 2017).

Readers not only read on their own, they also interact with each other. Different reading services, including the introductions of classic bibliography, exhibitions, lectures (including on-site), performance (including film and television documentary), are combined together. Besides spontaneous reading, librarians are trying to guide readers to read about a specific topic and discuss what they acquired from their reading. Readers can attend shows, listen to lectures, watch movies, read classic literature, enjoy music, and interact with famous experts of this topic. The traditional paper reading or electronic reading evolved into a new reading model combining sound, light, shape, and other forms. The new reading model is called the "topic-related multidimensional reading service."

Chinese academic libraries nowadays are trying to develop the topic-related multidimensional reading service. In this contribution, we used Tongji University Library and Nanjing Agricultural University Library as two cases to illustrate how Chinese academic libraries provide this service to its readers. Figure 1 shows the location of the two libraries.

Figure 1. Location of two libraries

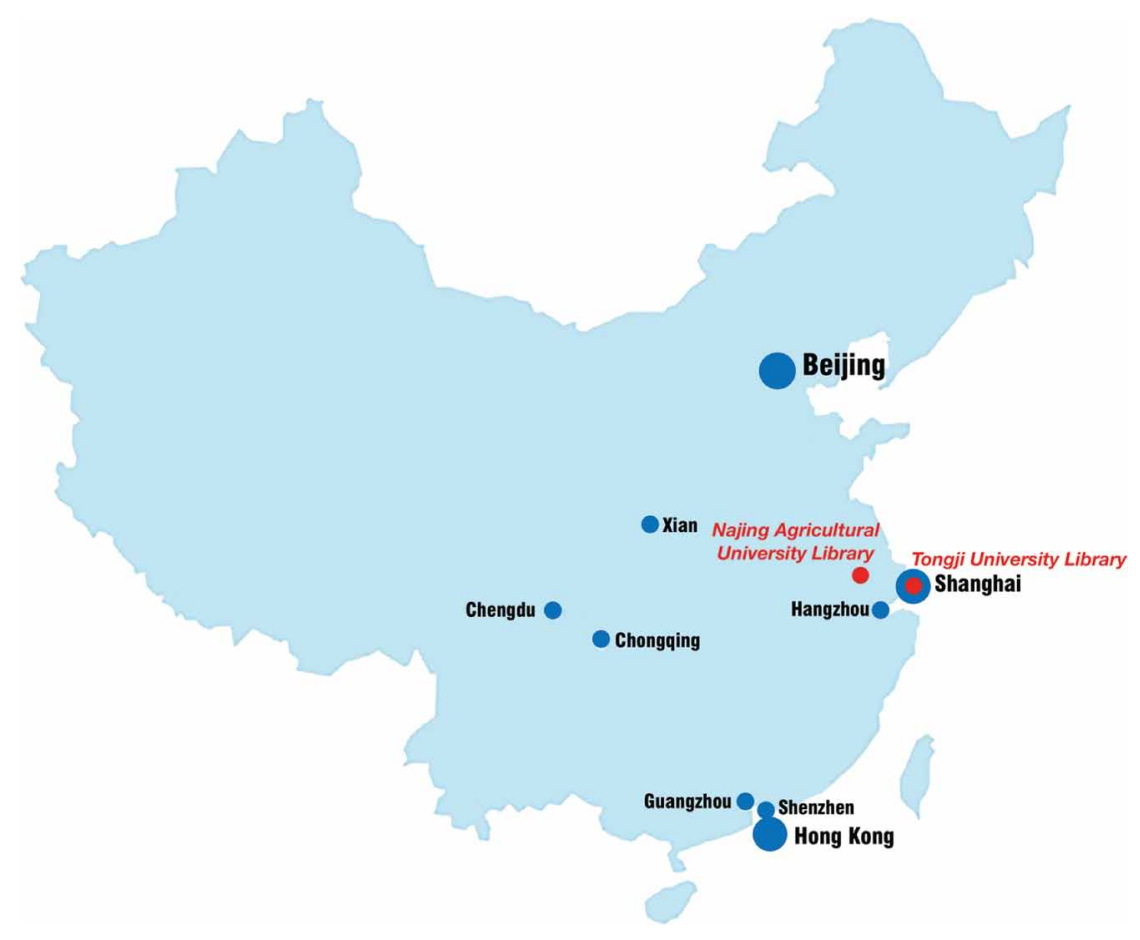




\section{THE DEVELOPMENT OF TOPIC-RELATED MULTIDIMENSIONAL READING}

Theoretically, the idea of topic-related multidimensional reading originated in the early $1990 \mathrm{~s}$. Fu (1991) discussed his preliminary perspective on topic-related multidimensional reading. Topic-related multidimensional reading refers to reading methods using visual, olfactory, auditory and other sensory organs to understand written materials from a multi-faceted and multi-angled level. This includes indepth reading of literary works. Later, the new technologies of acoustics and visualization were used to develop a new style of publications so that readers can listen to the story and see related images. This "multidimensional reading" concept was used to develop 3D stereoscopic publications for children. Gong (2009) suggested that primary and secondary schools should combine "classical reading," "continuous silent reading," and "parent-child reading" to develop "multidimensional reading." This could effectively build-up the students' academic foundation and enhance the teachers' and students' humanitarian spirit. To protect the literature resources of Sichuan local opera, He (2007) proposed to collect non-text resources, such as an artist's oral narrative and videos of opera, and establish a comprehensive database. Specific metadata should be used to reveal the resources so that they can be retrieved. Hyperlinks should be provided so that readers can access resources easily.

Practically, the "topic-related multidimensional reading" service originated from the "living library." In 2005, at the Malmö Library in southern Sweden, the activity of a "living person library" was carried out by allowing readers to "borrow" a living person. During a 45-minute conversation at the outdoor cafe, readers can gain some knowledge from this person. This person is also called the "living person book." Libraries that offer this service are called "living libraries" (Kinsley, 2010).

The Tongji University Library took the lead in improving the library's traditional service through combining the two original concepts above. In 2007, Tongji University Library held an exhibition on “Tongji People's Achievements" to celebrate the university's $100^{\text {th }}$ anniversary. In order to highlight the great achievements of Tongji University, the exhibition used multiple platforms (integrated archway, booth, shelves, display panels, and touch screen), along with multi-media (background music, text pictures, physical books, etc.), to give a full-round show of Tongji University's achievements during its 100-year history. The organizers called this a multidimensional display.

In 2008, to promote the traditional culture project---Peking Opera, the Tongji University Library launched the "Artistic China" and "Colorful China" multidimensional reading activities. The Chinese traditional drama and Chinese ink painting art were displayed multidimensionally. Some celebrities were invited to give presentations and performances. These activities attracted the attention and interest of university students. Since then, the service focuses on a specific topic.

In 2009, the idea of topic-related multidimensional reading began to mature. The library launched a series of "re-display Dunhuang" activities. Different methods, including exhibitions, listening to lectures, watching movies, reading, writing, and other ways, are used to let readers feel the Dunhuang culture. At this point, the library summarized experiences of "topic-related multidimensional display," and systematically put forward the concept of "topic-related multidimensional reading" (Guo and Zhang, 2010).

Funded by the grant "Tongji University the twelfth five-year cultural construction planning," the Tongji University Library's Topic-related Multidimensional Reading Service is promoted as a long-term supported project. The Ministry of Education of China use this service as a special base for National College Student Cultural Education.

Several topics have been carried out in the topic-related multidimensional reading service. "Classic Shanghai," which revealed the essence of Chinese urban culture - Shanghai culture; "Chinese memory," which displayed ancient architecture, ancient relics, calligraphy and painting, ancient music from different aspects; "feeling traditional culture," which displayed an application for the list of world heritage of Grand Canal, ancient Chinese mechanical achievements, and Song-Yuan-Ming Dynasties Chinese painting etc. 


\section{PRACTICES OF THE TOPIC-RELATED MULTIDIMENSIONAL READING IN CHINA}

Tongji University's "topic-related multidimensional reading service" has received more and more attention from Chinese libraries because of its innovative organizing methods, rich content, and popularity with readers. In many activities of the reading festival or the reading month of Chinese university libraries, a variety of reading methods have been implemented. We take reading activities from two universities as examples to illustrate practices of the topic-related multidimensional reading.

\subsection{Experiencing the Foreign Cultures at the Multidimensional Reading Service in Tongji University}

Besides displaying Chinese traditional culture in a multidimensional way, the Tongji University Library also actively promoted and introduced the culture of other countries. These activities were done at the occasion of important governmental, cultural, or university events. For example, "Approaching Tolstoy" was held to commemorate the 100th anniversary of the death of Russian writer Leo Tolstoy; the "Near India" activity was held to celebrate "Sino-Indian Friendship Year." To celebrate the $40^{\text {th }}$ anniversary of the establishment of diplomatic relations between China and the Federal Republic of Germany, the library hosted "experiencing German culture" (Liu \& Zhang, 2013); French culture, Italian culture, and British culture were also introduced to the readers. In these events, 'award-winning quest' was used to lead readers to in-depth reading.

Tongji University is one of the windows for cooperation between China and Europe. The university co-founded a China-Germany Institute with German government and a China-Italian Academy with the Italian government and Sino-Spanish Campus (SSC). SSC was co-founded by Tongji University, Polytechnical University of Madrid, and Polytechnical University of Catalonia, with headquarters in Tongji. As the window of communication and the platform of cooperation, SSC has the mission of enhancing and deepening the faculty and students' mobility and research cooperation among Tongji and Spanish universities and organizations and establishing collaboration with Latin America and the Caribbean based on the close relationship between these regions with Spain. SSC is promoting cultural communication between China and Spanish-speaking areas.

SSC has been established for five years by 2017. To celebrate the fifth anniversary of SSC, a topic-related multidimensional reading event named "Fiesta Spain" was co-sponsored by the library and SSC. The university's administrators and student representatives attended the ceremony.

The library presented four exhibitions: "Cultural of the Iberia-Spanish and Spanish-speaking countries," "the fifth anniversary of the establishment of the SSC," "Scenery views of Spain Painting Exhibition" and "Don Quixote." The library also organized a "dialog of translating Spanish," a Spanish cultural knowledge contest, the "Spanish language world" books for recommended reading, the Spanish movie nights, and other related activities.

At the same time, readers could also participate in the award-winning Spanish culture knowledge contest and "reading notes" contest through the library website or the third-party super cloud platform.

Through a series of rich and colorful reading activities, the university teachers and students joyfully tasted the unique Spanish culture. These events even attracted the attention of the industry. The first-place winner was awarded flight tickets to attend a summer school in Spain, sponsored by some business stores.

\subsection{Nanjing Agricultural University: "Reading Jinling, Dream Red Mansions" Topic-Related Multidimensional Reading Case}

Since 2009, Nanjing Agricultural University has held a "Month of Reading" activity that is scheduled around the World Reading Day every year. The activity was named with a Chinese 
poem "fu you shi shu qi zi hua," which means "one who is filled with knowledge always behaves with elegance." This activity includes book-recommendations, photography contest with the specific topic of "Reading is beautiful," celebrity's forum, knowledge contest, recognition of excellent readers, and other reading activities (Zhang, 2015). Over the years, activities become more rich and readers more enthusiastic.

In the activity for 2017, the library conducted a series of reading promotion events. To dig the traditional classic culture, the library took "Read Jinling • dream Red Mansions" as this year's theme. "A Dream in Red Mansions" is a classic novel, which is always referred to as a social and cultural encyclopedia. The city Jinling, called Nanjing today, is the place where "A Dream in Red Mansions" story took place. The "Reading Jinling, Dream Red Mansions" theme's reading activities aimed to stimulate readers' enthusiasm for classical reading by means of guiding the readers to explore the amazing food, clothing, building, garden, custom, etc. in the book as well as in the city.

The activity consisted of six Separate parts, as shown in Table 1.

Among them, "Interaction" was a plants appreciation activity held by the University Reading Association and Horticultural Association, called "dreaming back to the Red Mansions to find flowers." The activity consisted of Begonia nicknames, flower names, and flower languages. This section helps the participants understand this classic story through the real flowers and poetries.

"Sharing" is the section where the library invited guests and readers to share the plot, and the scenario or characters of the book which impressed them most during their reading.

"Visiting" is the field trip section. Readers were invited to visit the old house of Qing Dynasty's Jiangning Textile Bureau, where the author of the novel Cao Xue Qin was born, to understand the social background of the book.

"Tasting" is the section about reading the book from the view of Chinese cuisines. Some traditional Chinese cuisines that appeared in the book were taped as video, and showed to the public in the library.

"Lectures" was a real lecture given by the famous Chinese "Red Mansions" expert, Professor Zhichang Pan. The lecture's name is "A Dream in Red Mansions, why the book is so hot?" More than two hundred audiences attended this lecture, and it was quite successful.

"Contest" was the last section. The Nanjing Agriculture University Library organized an artistic graphic contest, and many students created excellent art works. The organizers were happy to provide awards to fifteen exquisite works.

\section{MEASURES TO IMPROVE THE EFFICACY OF TOPIC- RELATED MULTIDIMENSIONAL READING SERVICE}

Many Chinese libraries took advantage of activities such as "Month of Reading" or "Reading Festival," to promote "topic-related multidimensional reading services." The experiences have been accumulated, and some measures can improve its efficacy.

Table 1. "Reading Jinling, Dream Red Mansions" series of activities

\begin{tabular}{|l|l|}
\hline \multicolumn{1}{|c|}{ Activity Sections } & \multicolumn{1}{c|}{ Activity Content } \\
\hline Interaction & "dreaming back to the Red Mansions to find flowers" \\
\hline Sharing & Sharing a book - A Dream in Red Mansions. \\
\hline Visiting & Visiting old House of Qing Dynasty's Jiangning Textile Bureau. \\
\hline Tasting & Tasting the food of Red Mansions. \\
\hline Lectures & "A Dream in Red Mansions, why is it so hot?" \\
\hline Contest & "Reading Jinling, Dream Red Mansions" graphic contest. \\
\hline
\end{tabular}




\subsection{The Library Should Strengthen its Cultural Heritage and Cultural Education Functions}

Each library has its own specific facilities, talent, geography, and other comprehensive advantages. These form their own social and cultural heritage. Libraries should strive to expand their traditional service areas, to create much more popular services, exert their cultural education functions, and carry out cultural heritage work according to local conditions and traditions.

\subsection{Key Facts of Success: Choice of Theme and Interaction With Readers}

Adequate preparation is very important to be successful in "topic-related multidimensional reading" activities. It is a time and energy consuming process. Preparation work consisted of choosing topics, contacting cooperators and finding sponsors. One of the most important steps of preparation is the choice of topics. It is necessary to consider the reader's interests and needs, but one also needs to pay attention to the library's own resources and resource collection.

In the "topic-related multidimensional reading" activities, the library should attach great importance to the interaction with the readers. Interaction can stimulate readers' creativity and enthusiasm, and then the organizers can receive essays, comics, photography, and multimedia. Interaction also helps to improve learning outcomes, and enhances the effectiveness of topic-related multidimensional reading.

\subsection{A Guaranteed Strategy for Success: Establishing a Working Group System}

In order to ensure the long-term implementation of "topic-related multidimensional reading," the library should use the group working mechanism. Usually, a small coordination group will make a plan or suggest a topic about the "topic-related multidimensional reading." Once the project is confirmed, the preparatory work will begin. A temporary team is formed by staff chosen from various library departments. Team members will be assigned different tasks of the specific preparation. When the project is finished, team members will return to their regular positions, except the coordinators. A working group system effectively ensures the organization and implementation of the project, and does not consume too much manpower. The flexibility of this system is good not only for professional training, but also for improving the working enthusiasm of the staff.

\subsection{Resource Integration: Strengthen the Sharing of Resources, Enhancing Brand Awareness}

In order to lower the cost and share the resources, libraries could borrow materials such as display panels, literature, film, and videos from other libraries. For some larger projects, libraries can work together to put their resources into one project, using the working group strategy to deliver a tour show on each library. In addition, "topic-related multidimensional reading" offers the possibility for both the library and the industry to develop a more constructive relationship. For example, in 2017, Dunhuang fresco art boutique charity tour show was conducted in many cities in China. This tour show is a successful case of cooperation of libraries, and the Dunhuang Institute.

From the successful experience of universities such as Tongji University and Nanjing Agricultural University, it is important to hold activities regularly. For example, the Nanjing Agricultural University has held the one-month-long multidimensional reading service for 9 years. Meanwhile they tried to establish their own campus culture brand. The Nanjing Agricultural University built a "Month of Reading" brand entitled Wisdom in hold, elegance in mold, and a cartoon image has been designed to promote the services. In short, the topic-related multidimensional reading activities are becoming the cultural brand of whole libraries. 


\section{CONCLUSION}

The topic-related multidimensional reading services provides more potential for libraries. Theoretical and practical explorations suggest that academic libraries could integrate more resources from different areas to promote a deeper understanding of reading, and to make more contributions to knowledge transformation and innovation. We can even expect to use the same method to promote the scientific reading so that libraries can help scientists do their research (Liu \& Ji, 2009), and help doctors treat their patients (Robertson et al., 2008, Tukhareli, 2017). Libraries can then function as intellectual institutes (Liu, Wang \& Song, 2007). However, this will need much more intelligent librarians, and this is the biggest challenge. Therefore, more theories and methodologies are needed to ensure the service more successful in the direction.

\section{ACKNOWLEDGMENT}

We thank Robert Coelen from Stenden University of Applied Sciences, Netherland for his valuable comments. Yuxian Liu thanks Ismael Rafols for correcting the inaccurate narrative of the history in the early version of the essay in the Appendix. 


\section{REFERENCES}

Fan, B. (2014). Reading promotion and library science: Analysis on basic theoretical issues. Journal of Library Science in China, 5, 4-13. (in Chinese)

Fu, B. (1991). Preliminary perspective on multidimensional reading. Yindu Journal, 31(2), 53-56.

Gong, H. (2009). Promoting the cultural connotation of the school through "topic-related multidimensional reading." Journal of the Chinese Society of Education, 27(s1), 46-49. (in Chinese)

Guo, X., \& Zhang, H. (2010). Topic-related multidimensional reading - a new form of library service. Library Journal, 29(4), 38-39. (in Chinese)

He, Y. (2007). On the protection and exploitation of Sichuan literature resources. Journal of the Library Science Society of Sichuan, 28(6), 73-75. (in Chinese)

Kinsley, L. (2009). Lismore's living library: Connecting communities through conversation. Australasian Public Libraries and Information Services, 27(1), 20-25.

Liu, Y., \& Ji, C. (2009). Current use of foreign print periodicals in Chinese libraries and measures to increase the utility of these publications. Library Management, 30, 26-37. (in Chinese)

Liu, Y., Wang, G., \& Song, X. (2007). The evolvement of library to social intelligent institute and its essential characteristics. New Century Library, 2, 19-21. (in Chinese)

Liu, Y., \& Zhang, H. (2013). Three-Dimensional Reading: The new model of reader services. Library Development., 1, 42-44. (in Chinese)

Robertson, R., Wray, S. J., Maxwell, M., \& Pratt, R. J. (2008). The introduction of a healthy reading scheme for people with mental health problems: Usage and experiences of health professionals and library staff. Mental Health in Family Medicine, 5(4), 219-228. PMID:22477873

State Administration of Press, Publication, Radio, Film and Television. (2016). "13th Five-Year Plan" on Nationwide Reading. China News of Publication and Television, 2016-12-28. (in Chinese)

Tongji University Library. (2017). Topic-related multidimensional reading. Retrieved from http://www.lib.tongji. edu.cn/site/tongji/28faa97f-33f4-4ae7-a6be-a22635b9bcb3/index.html

Tukhareli, N. (2017). Therapy-based wellness program for healthcare providers: Using books and reading to create a healthy workplace. Journal of the Canadian Health Libraries Association, 38(2), 44-50. doi:10.5596/c17-010

Zhang, M; Fan, B. (2015). A study on the reading service of visually impaired people in china's public libraries. Library and information service, 61(3), 31-36.

Zhang, T. (2015). The construction of new service of "topic-related multidimensional reading" in public library. Journal of Library and Information Sciences in Agriculture, 27(7), 152-155. 


\title{
APPENDIX
}

\section{Library as a Cultural Melt Pot Bridging Rifts: Thoughts Floating Over the Opening Ceremony of Spanish-Related Multidimensional Reading Service}

\author{
Yuxian Liu, Institute of Higher Education at Tongji University, Shanghai, China
}

On April 21, 2017, the opening ceremony of the Spanish-related multidimensional reading service was held in the lobby of Tongji University Library. The service is titled with a romantic name: passionate enthusiasm on Spanish culture. At about 10:00 A.M., the invited guests, including Mrs. Lisbet Quesada Luna, the Consul-General of the Republic of Cuba in Shanghai; Mr. Carlos Quintana, the representative of the Spain Industry Development Agency in Greater China; Guo Meina, the cultural counselor of Consulate General of the Republic of Colombia in Shanghai; Professor Fekodi, representative of the principal of the Technical University of Madrid; and a representative of Consulate General of the Republic of Argentine in Shanghai, arrived to the lobby. They all greeted each other and had a cordial conversation. The cultural melting journey, which was initiated by the adventure supported by the Spanish royal in the fifteenth Century, now continued to ferment in the Tongji University and further adjoin the vast world into a small village.

The scene reminded me of the unforgettable visiting experience at SPRU of Sussex University in the United Kingdom. There were also many scholars from the South American countries such as Chile, Brazil, Columbia, and Argentina gathering in the lobby of the office building. The loneliness aroused from the exogenesis made us gather frequently. We held each other when we were homesick, and we kissed good-bye when we left each other, we were so close that we were like family members!

Their native language is Spanish, which I do not understand at all. I finally knew "Hola," a Spanish word equivalent to "hello" in English. My major collaborator left SPRU and worked in Spain at that time, and he visited SPRU from time to time as SPRU kept his title as a visiting fellow. I met him one day and said "Hola" to him because I thought he would be pleased when he was greeted in his native language. However, he said seriously to me, "I am not a Spanish, I am a Catalonian."

I knew little about Spanish culture, and could not understand the implication of his word. After that, he became very demanding: Whatever concerned Spain, he definitely claimed his point. Due to this, his colleagues in SPRU made fun of him behind his back. Later, I visited him in Spain and mentioned this to him, and he argued emotionally: "the colleagues do not speak my language, and have not undergone my situation. For their native culture has not been suppressed, how can they understand the pain of discrimination has brought to me?" At that moment, I saw tears bursting out in his eyes, but instantly his expression became steely. His resolution was so strong that he would, in my eyes, bear and accomplish his mission, even if bearing the mission is like taking the weight of Mount Everest on his shoulders. The power conveyed in his feeling was almost palpable.

Curiously, I spent some time studying Spanish history. It was not until then that I learned about a millennium long grudge between Spain and Catalonia in the long and circuitous history. One thousand years ago, Catalonia and the kingdom of Aragon encouraged and reinforced each other mutually, and hence established a good partnership. Since 1410, Aragon increasingly approached Castilla through the succession of the throne and the royal marriage. Catalonia's autonomy was decreased in the process and rebellions started, e.g. in 1641 the first Catalan republic was declared, only to be crunched by the Castillian and French armies. The War of the Spanish Succession broke out in 1701. This time Catalonia completely lost its kingdom and the laws of Castille were imposed. The Kingdom of Spain was created when the war was over in 1714. Catalonia was both tragic and heroic because they were cheated by the alliances of their own. Since then, Catalonia has been fighting for its autonomous rights. However, little success has been achieved. In the Franco regime (1933-1977), Catalans were not even allowed to speak their native language in public. 
We were born at the end of 1960s, and it was during this period that we spent our childhood. We were tightly swaddled in our mother's arms, speaking whatever mother told us to speak. We acquired the first view of the world from our mothers' tongue. Based on this view, we built up our faith, and our faith was rooted in the atmosphere of the native culture. We take in the strength from the atmosphere of culture and are prepared to practice this faith throughout our life. Hence, we love this culture as we love our life. While Catalonians of the same period would have to face the suppression of speaking the language which they inherited from the womb. Once they stepped into the society, their culture was devastated; hence, the faith upon which their lives were built was destroyed. This is just as if the life itself is denied by the society. How could they be reconciled with the society?

Then, I thought the rift between Catalonia and Spain could not be bridged, and the crisis could not be reconciled. It seemed that a split is the best arrangement for both of them.

There were two independent referendums in Europe in 2014: the Scottish and Catalonia Independence Referendums. The whole of Europe breathed the desire of independence. Scotland's referendum was endorsed by the government of England, and this drew intensive attention from all over the world. The Queen of England delivered a speech to urge the Scottish to deliberate their future. In the end, the Scottish said no to their Independence Referendum. On the contrary, Catalonia's referendum was not licensed by the Spanish authorities, and was finally cancelled under the pressure from all sides of Spain. But so far, the Catalonians are still trying to push forward the independence process by various means.

I am not sure what will happen in the future. There is an exhibition of the 5th anniversary achievements of the Sino-Spanish campus. I am surprised to find that the Sino-Spanish Campus (SSC) was co-founded by Tongji University, Polytechnical University of Madrid, and Polytechnical University of Catalonya, with the headquarters in Tongji. The professors and students of the three universities have been conducting multi-level exchanges. Although, while Spain and Catalonia are incompatible internally, they came together with a common mission in China. From Tongji library (which is in) Tongji University, or from Tongji University (which is in) Shanghai, or from Shanghai (which is in) China, or from China (which is in) Asia, or from Asia (which is in the world), we cast our sight far away to Europe. The vastness of Europe, in this line of sight, became a spot melting all differences. Madrid and Catalonia converged into one spot as two atoms in one molecule, and we cannot separate one from the other. Even the whole Earth became a lonely Pale Blue Dot in the picture taken by Voyager 1 from 6.4 billion kilometers away in the infinite expanse of the universe. There are many varieties of civilizations, politics, economics, and cultures in the Earth. Sometimes they have conflict, and sometimes they reconcile, hence there is often both love and hatred that arises between them. We thought it was insurmountable when we indulged ourselves deeply into the cultures. Nevertheless, everything comes to one spot when we break away from it, and eventually, we are all with each other.

In the view of history, all disputes are only an edged-tool to shape human's soul. The desire for autonomy and expansion planted in our hearts drives us to explore more expansively in the vast world. The road is not ready and there is no precedent to follow. We have to blaze a trail and break through all that in our own way. When the dust of history seals all the stories, only the soul remains in the monument of the human's spirit. Every piece of the stories is melted into a pot and make us become ourselves. This is just like the intense emotional experience that we had gone through in the youth to our lives. We thought we would be very virulent about the one who had broken our heart. However, when we age, with all the loving experience in retrospect, a faint smile will show in the corner of our eyes. We can feel a euphoria of aftertastes in the tip and dorsal root of our tongue. We could not help acknowledging these experiences. How pale our lives would have been if we had not had these stories! Eventually, all of the experiences, even the hatred, becomes the fortune of life.

The collaborator, who is firmly seeking national independence, showed me the Cathedral built in thirteenth century, Micalet and the Silk Market both established in fifteenth century in the central of Valencia. He particularly pointed out the ancient Roman imperial site to me. While the residual wall, which represented the victory and conquest in the history, is now trampled under the ground of 
Plaça de la Mare de Déu, and a Flower Offering to Mare de Déu dels Desamparats, which conveys the grace of a human being, is held annually. When we sat in the open coffee shop in the plaza de la virgin, lamenting the loss of life, how could we still be entangled in the past?

Since the Chinese cling to worship reunions, there is a cohesive force in Chinese culture. China, whose area is equivalent to Europe's, is still one country, after so many conflicts during thousands of years. On the contrary, Europeans are more willing to be independent, so Europe has been split into many countries. Which culture is better? God causes his sun to rise on the evil and the good, and sends rain on the righteous and the unrighteous. So when the history became reality, what we do is just to pray for goodness for all.

Returning to the opening ceremony, Spanish students performed a Spanish folk dance for the guests: A boy has a crush on a girl, and then sounds out her feelings and finally, they fall in love. As they get to know each other more, the conflict between them rises up, which leads them to break up. However, they begin to miss each other, and after communicating, they understand each other more profoundly and the harmony is restored. The performance vividly illustrated the cultural melting process of human history.

Chen Xin, the Chief librarian of the Tongji University Library, presents the ceremony. Mrs. Lisbet Quesada Luna and Mrs. Guo Meina deliver speeches. They all appreciate these kinds of cultural exchange events. They believe the library is a perfect place to hold these kind of events because the readers, who come from all different directions, would bring Spanish culture to each corner of the world. Because of this, they think this will blend their culture into different cultures.

Lv Peiming, the vice president of Tongji University, fully affirms the important roles the Spanish culture has made for the civilization of human beings, and hopes it would bear more fruit in the future.

At the end of ceremony, Ly Peiming announced the beginning of the Spanish-related multidimensional reading service. The crowd moved to enjoy the exhibitions showing the splendid Spanish culture. They brought their own culture while absorbing the other culture, and then these cultures melt together and disseminated all over the world as the crowd came out of the library and traveled around. People in the world is becoming members of one family, as they mutually understand.

Huiyan Tang is an associate research librarian and the assistant director of Nanjing Agricultural University Library. She has been working as a librarian for twenty-eight years. Tang received her PhD at Nanjing Agricultural University in 2014. She published dozens of publications, Tang's research interests include library management, information service, etc.

Yitao $\mathrm{Hu}$ is an associate research librarian at Nanjing Agricultural University, specializing in digital information organization and readers' services research. He received the Bachelor' Degree in Educational Technology at Xuzhou Normal University in 2003 and a Master's Degree in Library Science in 2011. He has published more than 10 research papers.

Suoling Zhu is an associate professor in College of Humanities \& Social Development at Nanjing Agricultural University. She received the PhD at Nanjing Agricultural University in 2011. Zhu's research interests include digital humanities, library assessment, information service, and bibliometrics.

Weiwei Li is a Master student at Higher Education Institute, Tongji University, China. She received her BA of Education from Yancheng Normal University, China in 2011. Her interests include Higher Education Management and Education Quality Assessment.

Qingkui Xi is an associate research librarian at Nanjing Agricultural University in China. Xi earned his PhD from Nanjing University of Science and Technology in China. His professional interests include assessment, document delivery and big data, etc.

Yuxian Liu is the corresponding author of this article. She is a research librarian at Tongji University Library. She obtained her PhD at Antwerp University, Belgium. She published more than 20 peer-reviewed articles in international journals and presented her work at several international conferences. She is a principal investigator of a NSFC project. 